\title{
Prevalence of HIV Infection and High-Risk Behavior Among Seasonal Migrant Workers in Kurdistan Province
}

\author{
Abdorrahim Afkhamzadeh ${ }^{1}$, Behzad Mohsenpour ${ }^{2}$, Farnaz Zandvakili ${ }^{3}$, Khaled Rahmani ${ }^{4}$, Mehdi Khunjam ${ }^{5}$ \\ 1-Associate Professor of Community Medicine, Social Determinants of Health Research Center, Research Institute for Health \\ Development, Kurdistan University of Medical Sciences, Sanandaj, Iran. ORCID: 0000-0003-4496-2466 \\ 2- Associate Professor of Infectious Diseases, Zoonosis Research Center, Research Institute for Health Development, Kurdistan \\ University of Medical Sciences, Sanandaj, Iran. ORCID: 0000-0001-8675-4492 \\ 3-Assistant Professor of Obstetrics and Gynecology, Department of Obstetrics and Gynecology, School of Medicine, Kurdistan \\ University of Medical Sciences, Sanandaj, Iran. ORCID: 0000-0003-4423-1559 \\ 4- Assistant Professor of Epidemiology, Liver and Digestive Research Center, Research Institute for Health Development, \\ Kurdistan University of Medical Sciences, Sanandaj, Iran. (Corresponding Author), Tel: 08733664644 \\ Email: khaledrahmani111@yahoo.com, ORCID: 0000-0002-0860-8040. \\ 5-MD student, Kurdistan University of Medical Sciences, Sanandaj, Iran. ORCID: 0000-0003-2806-9782
}

\section{ABSTRACT}

Background and Aim: Seasonal migrant workers are among the groups which are exposed to the risk of social harm, including HIV, because of entering into a new environment and staying away from their families. The purpose of this study was to investigate the prevalence of HIV and risky behavior among seasonal migrant workers in Kurdistan Province.

Materials and Methods: This cross-sectional study included 600 seasonal migrant workers in Kurdistan Province from 2018 to 2019. Data about high-risk behavior were collected by using a standard questionnaire. A rapid HIV test was used to detect HIV in the study participants. Using Stata software V14, data were analyzed by chi-square, Mann-Whitney U test, and logistic regression modeling.

Results: We did not find any positive rapid HIV test in the participants, in other words, the prevalence of HIV in the study population was zero. Ninety-two (15.3\%) individuals reported a history of drug abuse, among them one $(1.1 \%)$ had a history of drug injection. One hundred and twenty-one $(20.2 \%)$ of the individuals had a history of sexual behavior outside marriage. Multivariate analysis showed a significantly higher rate of risky sexual behavior among individuals with a history of drug abuse and single persons $(\mathrm{P}<0.001)$.

Conclusion: Although the prevalence of HIV infection among seasonal migrant workers was zero, the history of drug abuse and risky sexual behavior were high among this vulnerable group. Low knowledge about HIV is also a serious cause for concern. Continuous surveillance of risky behavior and administration of interventional programs for this group seems necessary.

Keywords: Migrant Worker, HIV/AIDS, Risky Sexual Behavior, Substance Abuse

Received: Nov 3, 2019

Accepted: May 19, 2020

How to cite the article: Abdorrahim Afkhamzadeh, Behzad Mohsenpour, Farnaz Zandvakili, Khaled Rahmani, Mehdi Khunjam. Prevalence of HIV infection and high-risk behavior among seasonal migrant workers in Kurdistan ProvinceSJKU 2021;25(6):103-114.

Copyright (C) 2018 the Author (s). Published by Kurdistan University of Medical Sciences. This is an open access article distributed under the terms of the Creative Commons Attribution-Non Commercial License 4.0 (CCBYNC), where it is permissible to download, share, remix, transform, and buildup the work provided it is properly cited. The work cannot be used commercially without permission from the journal 


\section{شيوع عفونت HIV و رفتار هاى برخطر در كاركران فصلى مهاجر استان كردستان}

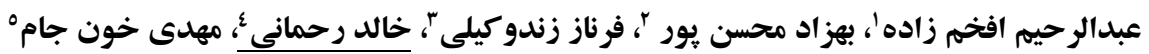

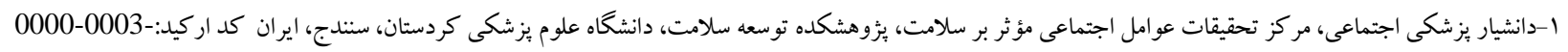
4496-2466

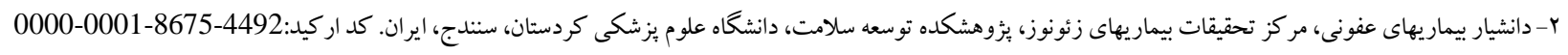

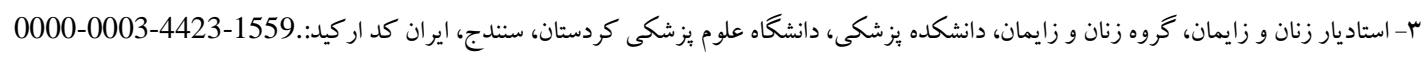

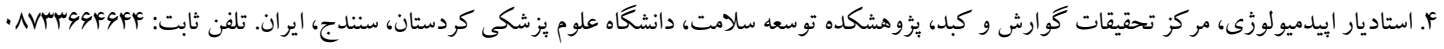

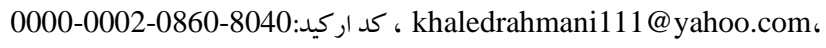

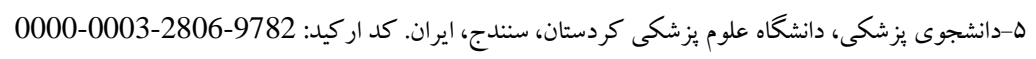

جكيده زمينه و هدف: كار گران مهاجر فصلى به دليل ورود به محيط زندگى جديد و دورى از خانو اده به عنوان يكى از گروه هاى در معرض

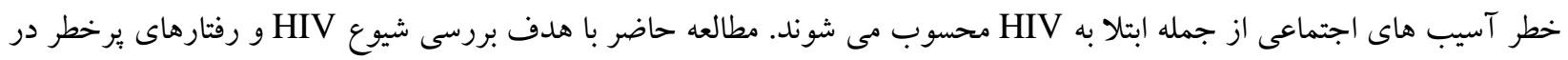
كار گران مهاجر فصلى استان كردستان انجام شد. مواد و روشها : مطالعه حاضر يك مطالعه مقطعى بود كه بر روى ..9 نفر از جمعيت كاركران مهاجر فصلى استان كردستان در سال

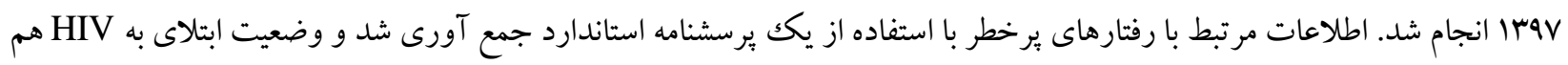

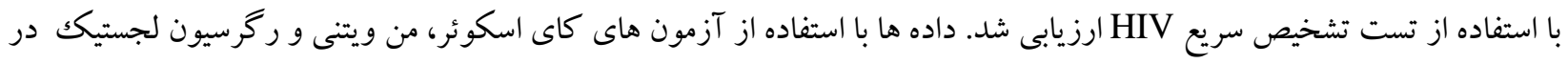
نرم افزار Stata نسخه ع أتحليل شد. يافته ها: تست تشخيص سريع HIV در هيجِكدام از افراد مورد بررسى مثبت نبود. به عبارتى شيوع HIV در افراد مورد مطالعه، صفر

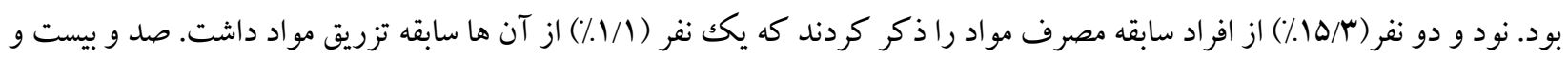
يكك نفر (Y/.Y/\%) از افراد سابقه رفتار جنسى خارج از جهارجوب ازدواج داشتند. در تحليل جند متغيره، رفتار يرخطر جنسى در افراد

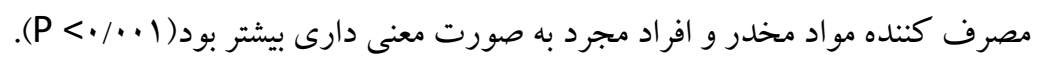

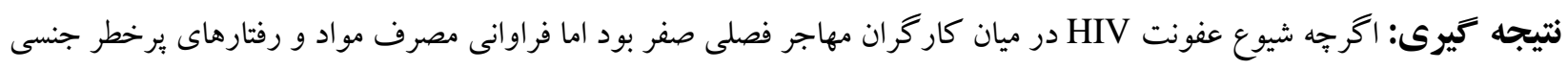



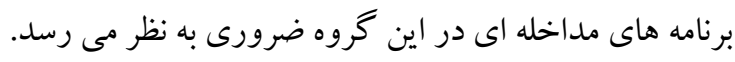

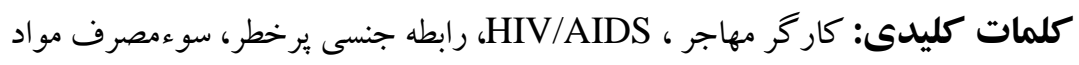

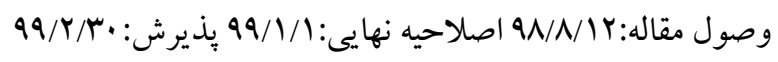


مهاجر ان نداند. همجنين تفاوتهاى فرهنگ و زبانى و نآشنايى با اجتماع مقصد، فهم اطلاعات ودسترسى به خدمات را براى جمعيت هاى جابجا شونده مشكل مى سازد (9, • (1).

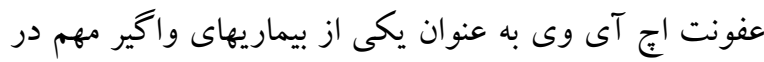
جامعه مطرح است و در بعضى از كشورها از جمله ايران يك بك به مشكل اصلى بهداشت عمومى محسوب مى شود(1). اين عفونت با رفتارهاى مخاطره آميز در ارتباط است كه بروز اين

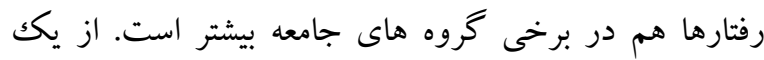
طرف، رفتارهاى مخاطره آميز و شناسايى افراد با رفتارهاى يرخطر، اهميت عمده اي براى مداخلات بهداشت عمومى دارد

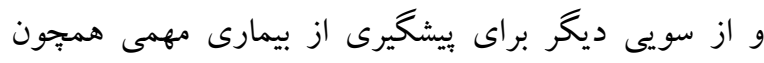

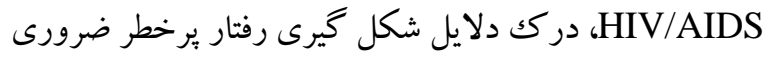
است (r, rاן). در يكك مطالعه متآناليز انجام شده در ايران نيز به ناكـافى بودن تحقيقات بيرامون رفتارهاى مؤثر بـر ابـتلا بـه ويسروس نقـص ايمنى انسانى اشاره شـــه اسـت و لـزوم انجـام مطالعـات در زمينه خصوصيات افراد با رفتارهاى برخطر جنسى

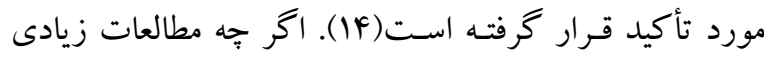
روى برخى گروه هاى برخطر در ايران همجيون معتادين،

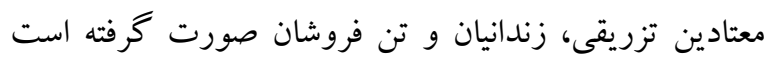
(1), (19)، اما بر اساس بررسى متون علمى موجود، تاكنون توجه

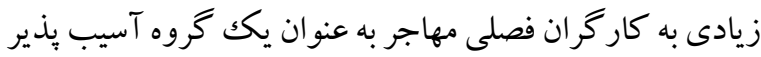

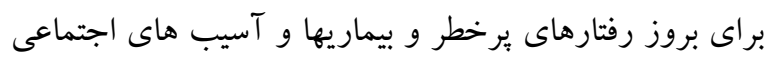

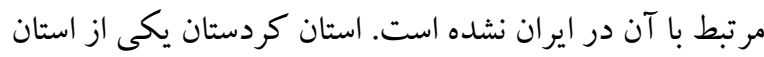
هاى كمتر صنعتى كشور است كه تعداد زيادى از جمعيت جوان

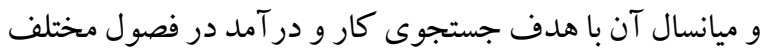
سال به استان هاى ديخر كشور مهاجرت مى كنند. مطالعه حاضر هاض با هدف بررسى شيوع ابتلاى به HIV/AIDS و همجنين رفتارهاى ير خطر در كارگران مهاجر فصلى استان كردستان بردي

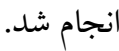



مقدمه مهاجرت، به عنوان يكى از بديده ها و واقعيت هاى زندگى مهدى بشرى، همواره وجود داشته است و امروزه نيز در ابعاد بين المللى و داخلى انجام مى شود. مهاجرت مى تو اند دلايل مختلفى داشته

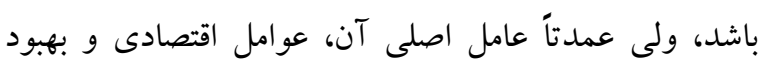

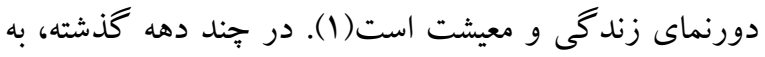
ويزّه بعد از اصلاحات ارضى در دهه ·f شمسى، توازن و تعادل ميان شهر و روستا در ايران از بين رفت و روستاها بيش از بيش به شهرها وابسته شدند كه اين وضعيت، زمينه را براى مهاجرت هاى روستا-شهرى فراهم كرد. اين مسئله امروزه نيز وجود دارد و روستاييان زيادى، به دلايل مختلف از جمله بهبود معيشت به كلان شهرهايى مانند تهران و شهرهاى اطر اف آن مهاجرت مى كنند(Y). بسيارى از مردانى كه مهاجرت مهى كنند (مانند

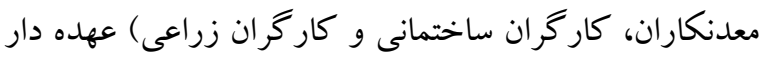

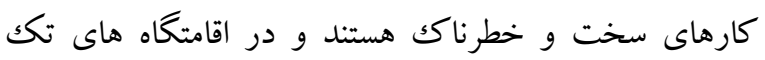
جنسيتى و فاقد فضاهاى خصوصى زندگى مى كنند(r). احساس تنهايى، خستكى و كمبود تفريح احتمال بروز رفتارهاى يرخطر از جمله اعتياد، رجوع به تن فروشان وروابط جنسى غير ايمن و به تبع آن ابتلا به HIV/AIDS يا امر اض مقاربتى را در ميان اين

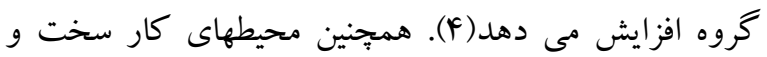
مردانه (مانند معادن) اغلب موجب بروز تلقينى خاص از

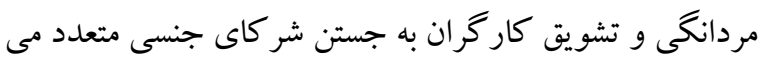

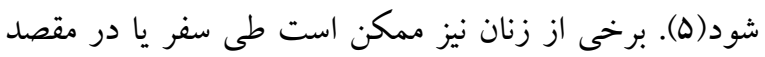
جهت به دست آوردن روزى، سريناه، مجوزعبور از مرزها، يا امكان كار در بازار رسمى و غير رسمى (زراعت يا دستفروشى) به روابط جنسى غيرايمن تن در دهند(4-1).

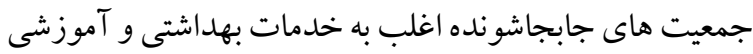
دسترسى محدودى دارند. در بسيارى مواقع ممكن است بخش



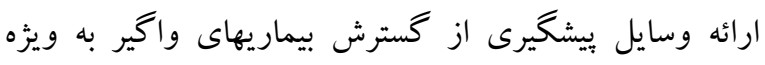
عفونت هاى منتقله از طريق جنسى از جمله HIV/AIDS به به بهري 
انتخاب تصادفى از ليست افراد صورت گرفت و در روستاها با

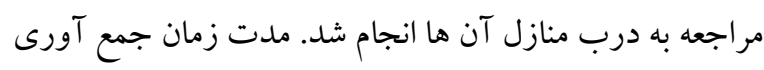
داده ها، باتوجه به ماهيت مطالعه حدود 9 ماه بود. در نقاط

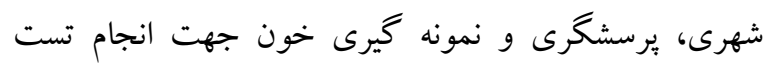
تشخيص سريع اجّ آى وى در مراكز و پايگاه هاى مشاوره بيماريهاى رفتارى هر كدام از شهرهاى محل اقامت كاركران



براى همه افراد شركت كننده در مطالعه يس از شرح اهداف مطالعه، رضايت كتبى آنها جهت شركت در مطالعه اخذ شد. افر اد بدون نام و نشان و تنها با يك كد مورد يرسشخرى، مشاوره

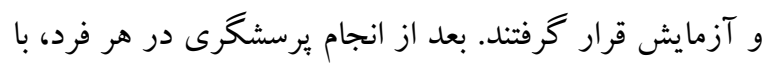
استفاده از تست تشخيص سريع اج آى وى (Rapid test) وضعيت ابتلاى فرد به اين ويروس مشخص گرديد. لازم به ذكر است كه در حال حاضر در نظام مراقبت كشورى برنامه كنترل HIV/AIDS

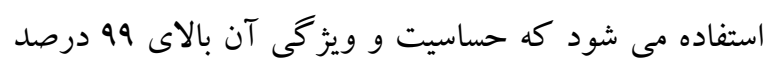
عنوان شده است. برسشنامه مورد استفاده براى جمع آورى داده

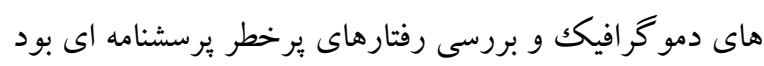

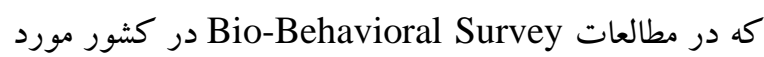

$$
\text { استفاده قرار گرفته است(YO) }
$$

If نجزيه و تحليل داده ها با استفاده از نرم افزار Stata نهخه انجام شد. ابتدا با استفاده از شاخص هاى توصيفى همجيون

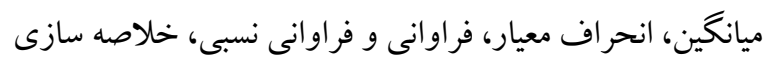
داده ها انجام شد. تحليل روابط بين متغيرهاى مختلف با رفتارهاى يرخطر (تحليل تكك متغيره) هم با استفاده از آزمون هاى من ويتنى يو (به دليل نرمال نبودن متغير سن)، كاى اسكوئر و تست دقيق فيشر استفاده شد. در نهايت براى بررسى ارتباط بين رفتار يرخطر جنسى با متغيرهاى معنى دار در آناليزهاى اوليه


و مقادير نسبت شانس، فاصله اطمينان و معنى دارى هر متغير محاسبه گرديد.
مطالعه ى حاضر از نوع مقطعى (Cross-sectional) بود كه به صورت توصيفى تحليلى انجام گرفت. جامعه مورد مطالعه شامل معال تمام كار گران فصلى مهاجر استان كردستان بود. افرادى كه وارد مطالعه مى شدند مى بايست در اصل ساكن استان كردستان بوده و سابقه حداقل يكك سال فعاليت را به عنوان كار گر فصلى داشته باشد. كارگران مورد بررسى .9 .9 نفر مرد بودند كه به صورت

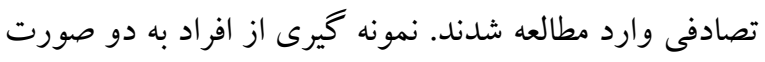
مختلف انجام شد. بر اين اساس در شهرها، با مراجعه به دفاتر كاريابى هر كدام از شهرستان هاى استان و اخذ ليست كار كران اندان فصلى آن ها و انتخاب تصادفى از بين ليست مذكور افراد وارد مطالعه شدند و در روستاها هم بر اساس ليست اعلامى توسط الما

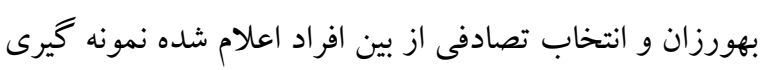

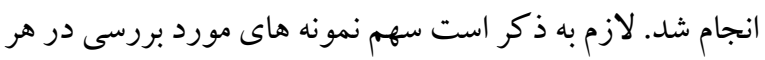

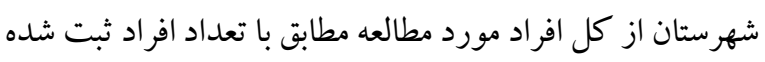
به عنوان كار خر فصلى در آن شهرستان بود. همانطور كه قبلا بيان شد طبق تعريف، هر فرد (مرد) بالاى 10 سال استان كه حداقل دوبار در طى زندگى جهت انجام كار و اخذ درآمد به استان هاى ديخر كشور و يا كشورهاى ديخر مراجعه كرده باشد و در هربار حداقل يكك ماه در آن محل اقامت داشته باشد و در مجموع سابقه فعاليت فرد به عنوان كارگر فصلى مهاجر بيش از يكك سال باشد معيار ورود به اين مطالعه را داشت. طراحى و اجراى اين مطالعه به تائيد كميته اخلاق معاونت تحقيقات و فناورى دانشگاه علوم يزشكى ورجى

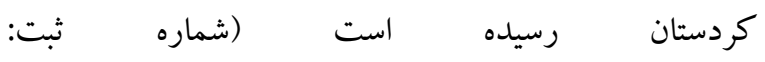
.(IR.MUK.REC.1396/211 جمع آورى داده هاى اين مطالعه با همكارى كارشناسان ايدز و

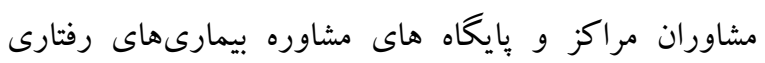

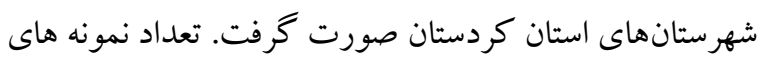
تخصيص يافته به هر شهرستان متناسب با بر آورد تعداد كار گران

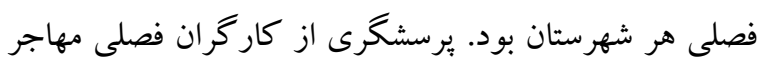
در شهرها با فراخوان تلفنى افراد از مراكز كاريابى بر اساس برس برس 
(1/1/ه) از افر اد سابقه زندان داشتند كه ميانگين و انحر اف معيار

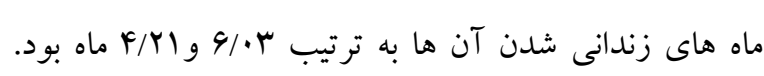
كمترين مدت زندانى شدن در افراد ها روز و بيشترين آن أن أ ماه

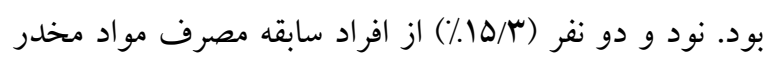

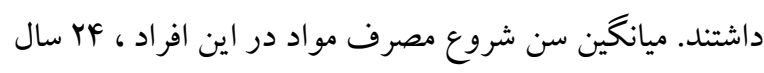

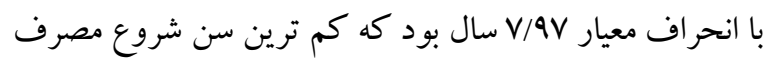
مواد با سالكى و بيشترين سن شروع مصرف مواد مخدر

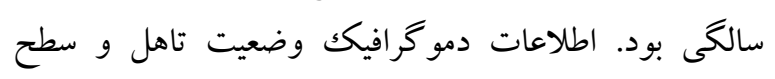
تحصيلات افراد مورد بررسى در جدول ا خلاصه شده است.

در اين مطالعه تعداد .49 نفر از كاركران فصلى مهاجر استان كردستان بررسى شدند كه ميانخين و انحراف معيار سن آنها به

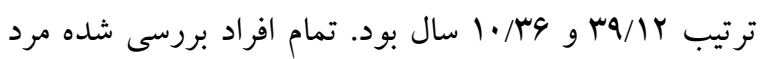

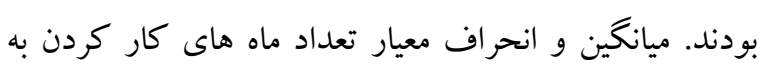

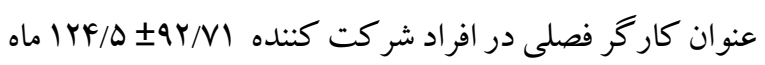
بود. بيشترين تعداد ماه فعاليت به عنوان كارگر فصلى مهاجر بA FA.

\begin{tabular}{|c|c|c|c|}
\hline درصد & فراوانى & سطح متغير & 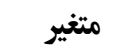 \\
\hline $0 \varepsilon / \Lambda$ & rrq & شهر & محل \\
\hline$\varepsilon 0 / r$ & PYI & روستا & سكونت \\
\hline 10.1 & 90 & ازدواج نكرده & وضعيت \\
\hline 11.r & EAY & ازدواج دائم & 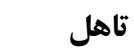 \\
\hline$\cdot .0$ & $r$ & متار كه & \\
\hline r & ir & طلاق كرفته & \\
\hline .0 & $r$ & همسر فوت كرده & \\
\hline 11.1 & vi & بع سواد & سطح \\
\hline 9 & $o \varepsilon$ & سواد خواندن و نوشتن & تحصيلات \\
\hline 19.5 & 117 & ابتدايى & \\
\hline rI.A & $|r|$ & سيكل و راهنمايى & \\
\hline $11 . r$ & TY & دبيرستان & \\
\hline IA.T & $1 \cdot 9$ & دييلم & \\
\hline r.r & $1 \varepsilon$ & كاردانى & \\
\hline $0 . Y$ & $r \varepsilon$ & كارشناسى & \\
\hline$\cdot . Y$ & $\varepsilon$ & ارشد و بالاتر & \\
\hline
\end{tabular}

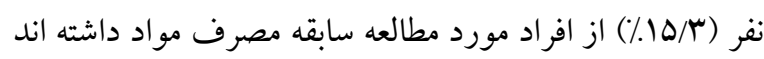

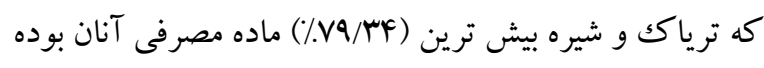

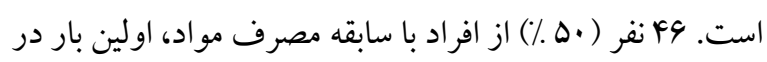

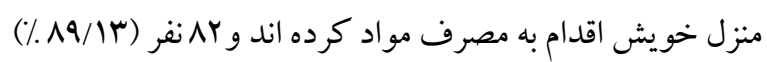

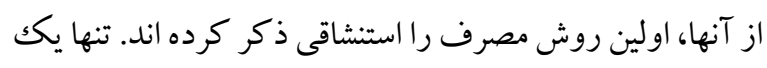

شيوع HIV/AIDS باتو جه به نتايج منفى تست ها، در همه افراد مورد مطالعه، صفر بود. رفتارهاى برخطر بررسى شده در افراد

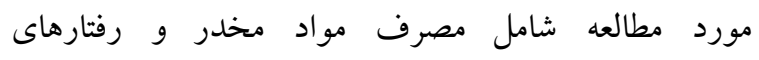
يرخطرجنسى بود كه نتايج توزيع فراوانى آن به ترتيب درد

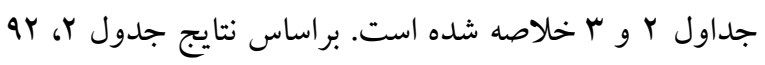




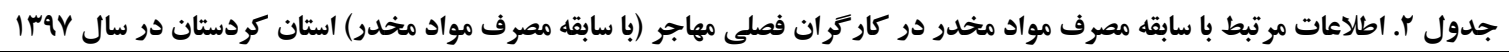

\begin{tabular}{|c|c|c|c|}
\hline درصد & 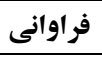 & سطح متغير & متغير \\
\hline & & & نوع ماده مخدر مصرفى \\
\hline$V Q / \mu F$ & vr & ترياك & \\
\hline $1 / \cdot 1$ & 1 & شيشه & \\
\hline $1 / \cdot 1$ & 1 & متادون & \\
\hline $19 / 4$ & 10 & جند نوع ماده مخدر & \\
\hline \multirow[t]{2}{*}{$r / I V$} & r & ساير (حشيش، ترامادول و..) & \\
\hline & & & اولين مكان مصرف مواد \\
\hline$\Delta \cdot$ & \&4 & 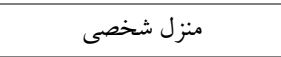 & \\
\hline HF/VA & rr & منزل دوستان & \\
\hline$r / I V$ & r &  & \\
\hline$r / Y q$ & r & هنكام راندةگى & \\
\hline \multirow[t]{2}{*}{ Q/V^ } & 9 & ساير & \\
\hline & & & اولين روش مصرف مواد \\
\hline $91 / \%$ & $\wedge F$ & استشناقى & \\
\hline r/Yq & $r$ & بيب" & \\
\hline \multirow[t]{2}{*}{$\Delta / F T$} & $\Delta$ & 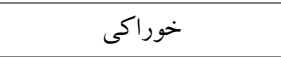 & \\
\hline & & & مصرف كننده كنونى مواد (در زمان انجام مطالعه) \\
\hline$r \mu / F V$ & f. & بله & \\
\hline$\Delta q / \Delta r$ & $\Delta r$ & خير & \\
\hline
\end{tabular}

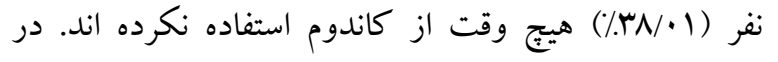
دسترس نبودن كاندوم، عدم تمايل شخصى و مخالفت شريك جنسى مهمترين دلايل عدم استفاده از كاندوم بوده است (جدول

(r

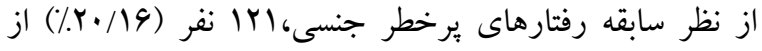
شركت كنند كان در مطالعه، رابطه جنسى خارج از جهارجّوب ازدواج داشته اند كه از اين افراد، تنها ها نفر (qس/Y اI\%) هميشه

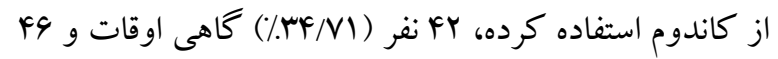


فالد (صمانى

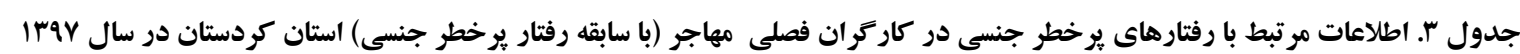

\begin{tabular}{|c|c|c|c|}
\hline 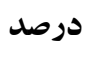 & فراوانى & سطح متغيير & \multirow{5}{*}{ 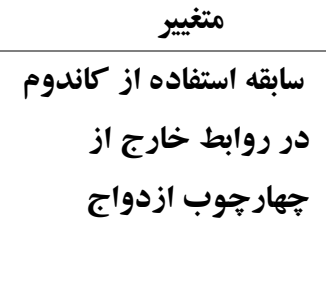 } \\
\hline $1 r / r q$ & 10 & هميشه & \\
\hline$r \varepsilon / v 1$ & $\varepsilon r$ & Fاهى اوقات & \\
\hline $\mathrm{r} \boldsymbol{N} / \cdot 1$ & $\varepsilon \eta$ & هيج وقت & \\
\hline IE/AY & 11 & به ندرت & \\
\hline \multirow[t]{2}{*}{ os/Vr } & $0 \wedge$ & نداشتن / در دسترس نبودن & \multirow{6}{*}{ داريل عدم استفاده از } \\
\hline & & كاندوم & \\
\hline$r \cdot /$ Yo & rr & عدم تمايل شخصى & \\
\hline $17 / 91$ & 11 & مخالفت شريك جنسى & \\
\hline $0 / 77$ & 7 & عدم اهميت استفاده از كاندوم & \\
\hline $1 / 1 \Lambda$ & $r$ & كران بودن كاندوم & \\
\hline $9 / 9$ & ir & در ازاى يول & \multirow{5}{*}{  } \\
\hline $77 / 9 \varepsilon$ & 11 & 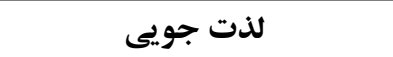 & \\
\hline \multirow[t]{2}{*}{$11 / 0 \mathrm{r}$} & $1 \varepsilon$ & هردو (در ازاى يول و لذت & \\
\hline & & جويى) & \\
\hline $11 / 0 \gamma$ & $1 \varepsilon$ & بع ياسخ & \\
\hline $1 r / r q$ & 10 & افزايش داشته & \multirow{4}{*}{ جنسى دوند تعداد شر كاى } \\
\hline$\varepsilon \wedge / Y\urcorner$ & 09 & كاهش داشته & \\
\hline 17/or & $r \cdot$ & بدون تغيير & \\
\hline Tr/MI & $r Y$ & بع ياسخ & \\
\hline $1 \cdot / v \varepsilon$ & Ir & بله & \multirow{2}{*}{ بابقه رابطه جنسى صورت كروهى } \\
\hline ^q/ro & $1 \cdot 1$ & خير & \\
\hline
\end{tabular}

به استفاده از كاندوم براى بيشخيرى از عفونت هاى آميزشى از جمله اج آى وى نداشتند. رابطه بين متغيرهاى مسـتقل با فراوانى رفتارهاى يرخطر (رابطه جنسـى خارج از جارجوب ازدواج و مصسرف مواد مخدر) در جدول F خلاصه شده است.
در بين افراد مورد بررسـى، Y Iا نفر (N/V/) هيج دانشـى در

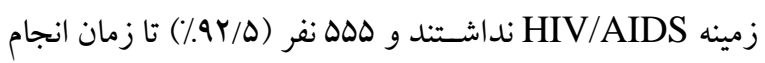
اين مطـالعـه از نظر HIV/AIDS مورد بررسـى قرار نخرفته بودند. يكصد و شصت و دو نفر (YV) از آنها هم هيج اعتقادى 
جدول ع. عوامل موثر بر بروز رفتارهاى يرخطر (رابطه جنسى خارج از جارجوب ازدواج و مصرف مواد مخدر) در كاركران

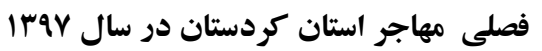

\begin{tabular}{|c|c|c|c|c|c|c|c|}
\hline \multirow[t]{2}{*}{$\begin{array}{c}\mathrm{P} \\
\text { value }\end{array}$} & \multicolumn{2}{|c|}{ مصرف مواد مخدر } & \multirow[t]{2}{*}{$\mathrm{P}$ value } & \multicolumn{2}{|c|}{ 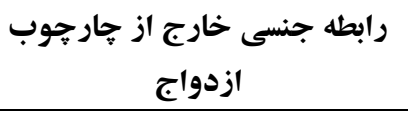 } & \multirow{3}{*}{\multicolumn{2}{|c|}{ سن (سال) - ميانكين }} \\
\hline & خير & بلى & & خير & بلى & & \\
\hline$\because \cdot 1 \cdot+1$ & $r_{N / T V} \pm 1 . / 19$ & $R \Gamma / A r \pm 1 \cdot / r F$ & $* \cdot / . r$ & $r q / \Delta q \pm 1 \cdot / r \Delta$ & $r V / r 9 \pm 1 \cdot / 9 r$ & & \\
\hline \multirow[t]{3}{*}{ 米类・/ $/ r$} & & & 米米・ $/ \cdots 1$ & & & & وضعيت تاهل \\
\hline & $F \cdot F(\lambda r)$ & $\Lambda r(I V)$ & & $F \cdot V(\Lambda r / 9)$ & $\lambda \cdot(\mid q / 4)$ & متاهل & \\
\hline & $1 . F(9 Y)$ & $9(\wedge)$ & & $V Y\left(\mathcal{G T}^{\top} / \mathrm{V}\right)$ & $F I(r g / r)$ & مجرد & \\
\hline \multirow[t]{5}{*}{ 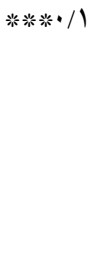 } & & & 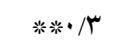 & & & & تحصيلات \\
\hline & $\Delta q(\mathrm{VN} / \mathrm{q})$ & $10(Y / 1)$ & & $4 \cdot(\lambda F / \Delta)$ & $11(1 \Delta / \Delta)$ & بى سواد & \\
\hline & $F \cdot F(\Lambda F / V)$ & $\operatorname{Vr}(1 \Delta / \Gamma)$ & & HNI (VQ/৭) & $99(r \cdot / 1)$ & زير دييلم & \\
\hline & & & & & & و دييلم & \\
\hline & $r \Lambda(Q Y / Y)$ & $F(V / V)$ & & $r \Lambda\left(r^{r} / 1\right)$ & If $(Y G / Q)$ & آكادميك & \\
\hline$\cdot / \cdot \cdot 1$ & & & 拳㫧 $\cdot / \cdot r$ & & & & سابقه زندان \\
\hline \multicolumn{8}{|l|}{ 米粠 } \\
\hline & $\operatorname{lq9}(M / \Gamma)$ & $\operatorname{Gr}(11 / V)$ & & $\operatorname{RHF}(\Lambda \mathrm{I} / \mathrm{V})$ & $9 \vee(\mid N / \Gamma)$ & خير & \\
\hline & $r q(07 / 0)$ & $r \cdot(\varepsilon r / 0)$ & & $\varepsilon 0(70 / T)$ & $r \varepsilon(r \varepsilon / \Lambda)$ & بلى & \\
\hline$\cdot 1 \cdot \cdot 1$ & & & - & - & - & & رابطه جنسى خارج \\
\hline$* *<$ & & & & & & & از جارجوب ازدواج \\
\hline & $\varepsilon r q(\wedge q / 7)$ & $0 \cdot(1 \cdot / \varepsilon)$ & - & - & - & خير & \\
\hline & $\mathrm{Vq}(70 / \pi)$ & $\varepsilon r(r \varepsilon / Y)$ & - & - & - & بلى & \\
\hline
\end{tabular}

بر اساس نتايج خلاصه شده در جدول F، فراوانى رفتار برخطر ارتباط معنىدارى با فراوانى رفتارهاى يرخطر داشتند. داشتن

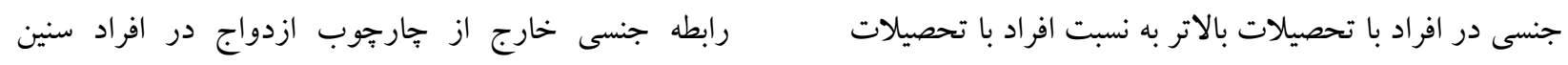

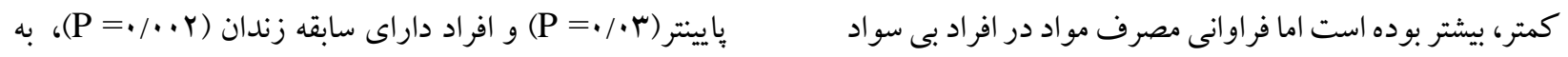
و تحصيلات پِايين تر بيشتر بوده است، اكر جه از نظر آمارى طور معنى دارى بيشتر بود. براى در كك بهتر از تحليل روابط بين

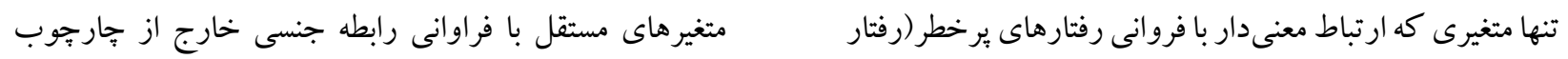

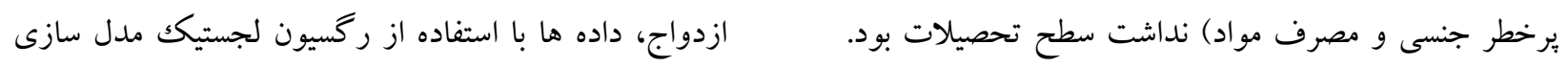

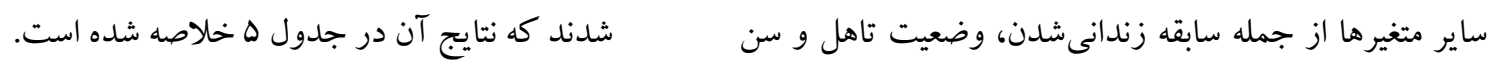




\begin{tabular}{|c|c|c|c|c|c|}
\hline \multicolumn{2}{|c|}{ Adjusted } & \multicolumn{2}{|c|}{ Unadjusted } & \multirow{2}{*}{ سطوح متغير } & \multirow{2}{*}{ متغير } \\
\hline P value & *OR $(95 \% \mathrm{CI})$ & P value & OR $(95 \% \mathrm{CI}) *$ & & \\
\hline$\cdot 11$ & $\cdot / 91(\cdot / 90-1 / \cdot 1)$ & $\cdot / \cdot r$ & $\cdot / 91(\cdot / 99-\cdot / 99)$ & & سن \\
\hline- & 1 & $\cdot / \cdot r$ & 1 & ندارد & سابقه زندان \\
\hline$\cdot / 1$ & $1 / 91(\cdot / A V-r / .1)$ & & $r / r q(1 / r q-r / 1 \cdot)$ & دارد & \\
\hline- & 1 & - & 1 & بى سواد & تحصيلات \\
\hline$\cdot / 9$ & $1 / \cdot 1(\cdot / F \Delta-Y / Y F)$ & $\cdot / \mu$ & $1 / r V(\cdot / V \cdot-r / V I)$ & زير ديّلم و ديِلم & \\
\hline$\cdot / \mathrm{V}$ & $1 / 10(\cdot / 4 \cdot-r / \mu 1)$ & $\cdot / 1$ & $r / \cdot 1(\cdot / \Lambda r-r / \Lambda \Lambda)$ & آكادميكى & \\
\hline - & 1 & - & 1 & متاهل & وضعيت تاهل \\
\hline$<\cdot / \cdot 1$ & $\mu / I F(I / \Lambda \cdot-\Delta / F V)$ & $<\cdot / \cdot \cdot$ & $r / q \cdot(1 / \Lambda F-F / \Delta \Delta)$ & مجرد & \\
\hline - & 1 & - & 1 & خير & مخرف مواد \\
\hline$<\cdot / \cdot 1$ & $\Delta / q 1(r / F r-1 \cdot / / V)$ & $<\cdot / \cdot \cdot$ & $F / \Delta G(Y / \Lambda F-V / T F)$ & 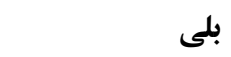 & \\
\hline
\end{tabular}

OR: Odds Ratio (نسبت شانس), CI: Confidence Interval(فاصله اطمينان)

آى وى در اين گروه مورد بررسى قرار گيرد. نتايج به دست


بررسى، شيوع رفتارهاى يرخطر در اين خروه بالاست. در مطالعه حاضر شيوع HIV در بين كاركران فصلى مهاجر صفر بود. براساس مطالعات انجام شده در دنيا مهاجرت

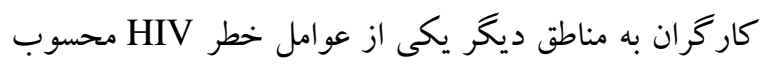
مى شو د. وضعيت ابتلا به HIV در اين گروه به وضعيت ابتلا در

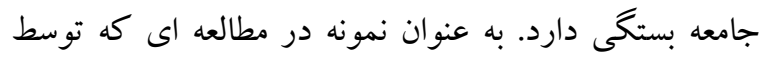
Margaret Giorgio

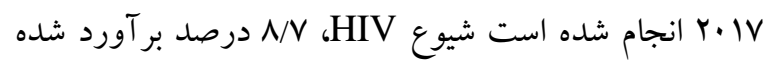
است(1). . درمطالعه ديخرى كه توسط Cynthia در ميان كاگران موزامبيكى كه در يكى از معادن آفريقاى جنوبى انجام

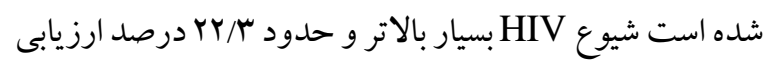
شده است. در مطالعه اى ديخر كه روى ..اكودك كار و و

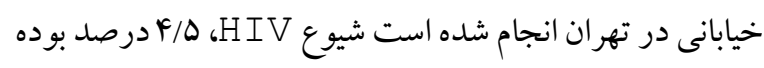
است(19). براساس نتايج به دست آمده، ب/ه1\% از افر اد سابقه مصرف مواد داشته اند كه يك نفر (1/1\%) از آن ها سابقه مصرف مواد به صورت تزريقى داشت. در مطالعه اى كه در New Orleans
نتايج مدل سازى رگرسيون لجستيك (جدول ه) نشان مى دهد كه شانس داشتن رفتار برخطر جنسى (رابطه جنسى خارج از مدردي

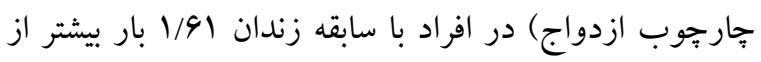
افراد بدون سابقه زندان بوده است اگر جهه اين يافته از نظر

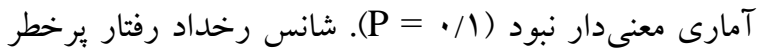
جنسى در افراد مجرد نسبت به متاهل (FR = (OR و در افراد مصرف كننده مواد مخدر (OR= (O/A)) به صورت معنى دارى

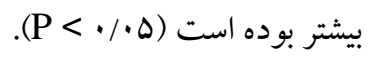
كارگران فصلى مهاجر به دلايل مختلف از جمله تغيير مكان، دورى از خانواده، همنشينى با افراد مختلف و ورود به مناطق متفاوت از نظر فرهنكى يكى از گروه هاى آسيب يذير در زمينه

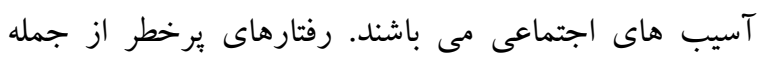
مصرف مو اد مخدر و برقرارى روابط جنسى خارج از جارجوب دي ازدواج و بيماريهاى منتقله از طريق خون و ترشحات جنسى از جمله اج آى وى و هياتيت هاى ويروسى B و C، تهلديدى جدى براى سلامتى اين گروه از افراد محسوب مى شوند(IV). در مطالعه حاضر سعى شد وضعيت رفتارهاى برخطر و شيوع أج 
شده است و مى تواند شواهدى اوليه از وضعيت رفتارهاى يرخطر در اين گروه براى سياستخذاران سلامت فراهم كند. از نقاط قوت مطالعه حاضر، مى توان به طراحى مناسب مطالعه از جمله حجم نمونه بالا، توجه به جمعيت كارگرى مناطق مختلف استان در اختصاص تعداد نمونه ها به مناطق و انتخاب تصادفى افر اد از ميان ليست كار گر ان فصلى هر منطقه اشاره كرد. استفاده از تست تشخيص سريع براى تعيين وضعيت ابتلاى افراد به HIV نقطه قوت ديخر مطالعه بود كه بدون نياز به بروسيجرهاى تهاجمى و تنها با اخذ دو قطره خون ابتلا يا عدم ابتلاى فرد به تعيين مى شد. عمده محدوديت مطالعه، كم بر آوردى HIV رفتارهاى يرخطر در اين كروه است كه ممكن است خود كزارش دهى افراد به دليل محدوديت هاى فرهنكى ناشى از انخك وارد شده به رفتارهاى يرخطر علت اين مورد باشد. اگر جִه تلاش محققان بر اين بود كه با استفاده از همكارى مشاوران دوره ديده مراكز وبايگاه هاى مشاوره بيماريهاى رفتارى تا حدودى ميزان كم گز ارش دهى كاهش يابد.

\section{نتيجه كيرى}

براساس نتايج مطالعه حاضر، اگرجه شيوع عفونت HIV/AIDS صفر بوده است اما سابقه ى مصرف مواد و رفتارهاى برخطر جنسى در اين افراد بالاست. رفتارهاى برخطر جنسى اين افراد مى تواند زمينه را براى ابتلاى به عفونت HIV/AIDS و همجينين ساير عفونت هاى منتقله از طريق جنسى فراهم سازد.


براى سياستخزاران سلامت محسوب مى شود. علاوه بر اين موارد، براساس نتايج به دست آمده، ميزان دانش اين گروه يرخطر در زمينه HIV/AIDS يائين است. بنابراين لازم است برنامه هاى مداخله اى در راستاى افزايش آكاهى اين افراد در مورد HIV/AIDS و راه هاى انتقال آن و همجينين راه كارهاى
و توسط Kissinger انجام شده نشان داده شده كه تنها در يك هفته قبل از شروع مطالعه 19/9 (درصد از كاركران مهاجر مارى

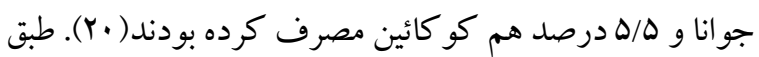
نتايج مطالعه حاضر، افراد مجرد در معرض خطر بيشترى براى داشتن رفتارهاى برخطر جنسى بودند كه متاهل نبودن و دور

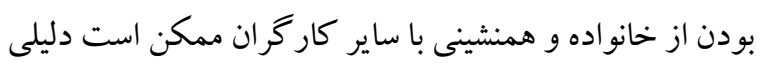

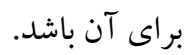

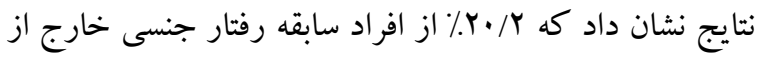
جهارجوب ازدواج داشته اند. نتايج مطالعه حاضر با مطالعه Saggurti



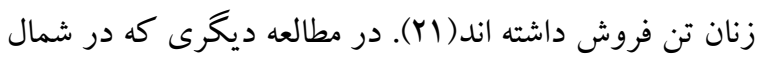
اتيويى روى كارگران مهاجر انجام شده شيوع رفتار جنسى

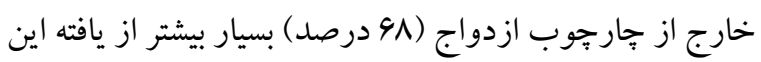
مطالعه بوده است(YY).

ميزان آكاهى كار گران مورد مطالعه در زمينه HIV در مطالعه

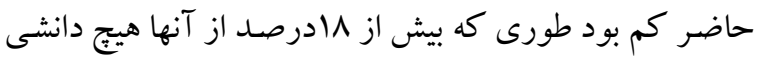

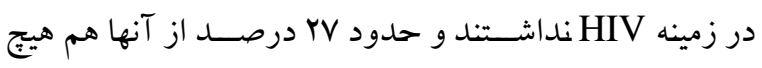
اعتقادى به كاندوم به عنوان يكك وسيله بيشگيرى از انتقال ايدز

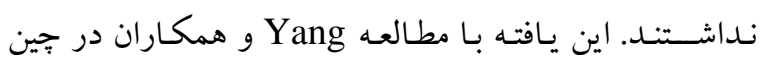

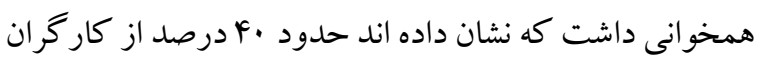
مهاجر دركك صسحيحى از كاهش خطر انتقال عفونت از طريق استفاده از كاندوم نداشتند(س). يكى از اجزاى نظام مراقبت HIV/AIDS براى ايران و و كشورهاى با وضعيت مشابه ايران كه الكوى متمركز عفونت را دارند توجه به نظام مراقبت رفتارهاى يرخطر مى HIV باشد(YU, YF). براساس شواهد علمى موجود افراد جوياى كار

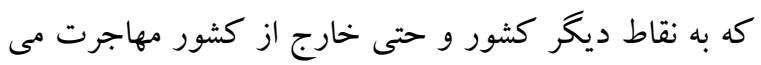
كنند يكك گروه يرخطر از نظر ابتلا به HIV محسوب ماته

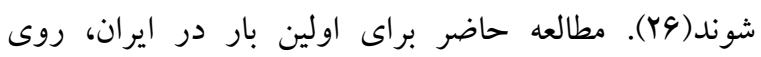

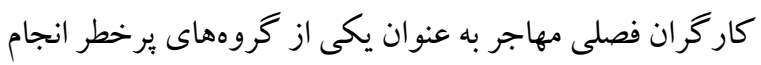




$$
\begin{aligned}
& \text { مقاله حاضر حاصل يكك بايان نامه بز شكى عمومى مصوب در } \\
& \text { مناسب براى بيشگيرى از بروز انواع رفتارهاى برخطر مد نظر }
\end{aligned}
$$

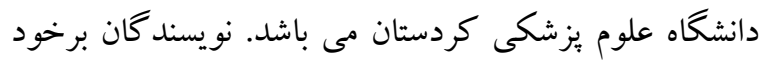

$$
\begin{aligned}
& \text { مسئولان و سياست گذاران سلامت قرار گيرد. }
\end{aligned}
$$

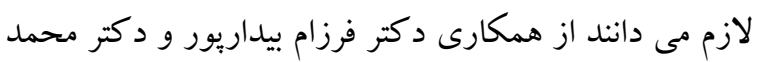

$$
\begin{aligned}
& \text { كريمى در اجراى اين مطالعه تشكر و قدردانى كنند. }
\end{aligned}
$$

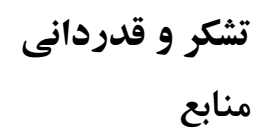

1.Bihamta N, Soffianian A, Fakheran S, Gholamalifard M. Using the SLEUTH urban growth model to simulate future urban expansion of the Isfahan metropolitan area, Iran. J Indian Soc Remote Sens. 2015;43(2):407-14.

2.Gholipour M. The study of rural-urban migration in Iran and the consequences of this migration. Adv Nat Appl Sci. 2015;9(2):1-7.

3.Du Guerny J. Multisectoral Responses to Mobile Populations' HIV Vulnerability: Examples from People's Republic of China, Thailand and Viet Nam: a Collection of Papers at a Special Session of the 6th Asia Pacific Social Sciences and Medicine Conference, Kunming, Yunnan, People's Republic of China: UNDP South East Asia HIV and Development Programme; 2003.

4.El-Bassel N, Gilbert L, Shaw SA, Mergenova G, Terlikbayeva A, Primbetova S, et al. The Silk Road Health Project: how mobility and migration status influence HIV risks among male migrant workers in Central Asia. PloS one. 2016;11(3):e0151278.

5.del Amo J, Erwin J, Fenton K, Gray K. AIDS \& Mobility: Looking to the Future. Migration and HIV/AIDS in Europe-Recent developments and needs for future action Woerden, The Netherlands: European Project AIDS \& Mobility. 2001.

6.Kwon JH. The work of waiting: love and money in Korean Chinese transnational migration. Cult Anthropol. 2015;30(3):477-500.

7.Oso Casas L. Money, sex, love and the family: Economic and affective strategies of Latin American sex workers in Spain. J Ethnic Migrat Stud. 2010;36(1):47-65.

8.Plambech S. Sex, deportation and rescue: Economies of migration among Nigerian sex workers. Fem Econ. 2017;23(3):134-59.

9.Langlois EV, Haines A, Tomson G, Ghaffar A. Refugees: towards better access to health-care services. The Lancet. 2016;387(10016):319-21.

10.Wild V. Universal access to health care for migrants: applying cosmopolitanism to the domestic realm. Publ Health Ethics. 2015;8(2):162-72.

11.Moradi G, Mohraz M, Gouya M, Dejman M, Alinaghi S, Rahmani K, et al. Problems of providing services to people affected by HIV/AIDS: service providers and recipients perspectives. East Mediterr Health J. 2015;21.( (')

12.Coughlin MM, Beck AS, Bankamp B, Rota PA. Perspective on Global Measles Epidemiology and Control and the Role of Novel Vaccination Strategies. Viruses. 2017;9(1):11.

13.Mustanski B, Garofalo R, Herrick A, Donenberg G. Psychosocial health problems increase risk for HIV among urban young men who have sex with men: preliminary evidence of a syndemic in need of attention. Ann Behav Med. 2007;34(1):37-45.

14.Nedjat S, Feyzzadeh A, Asghari S, Keshtkar A, Heshmat R, Majdzadeh S. HIV risk factors in Iran; systematic review, meta-analysis and generalized impact fraction approaches. Payesh. 2007;6(1):45-54.

15.Haghdoost AA, Mostafavi E, Mirzazadeh A, Navadeh S, Feizzadeh A, Fahimfar N, et al. Modelling of HIV/AIDS in Iran up to 2014. J AIDS HIV Res. 2011;3(12):231-9. 
16.Razzaghi E, Nassirimanesh B, Afshar P, Ohiri K, Claeson M, Power R. HIV/AIDS harm reduction in Iran. The Lancet. 2006;368(9534):434-5.

17.Deane KD, Parkhurst JO, Johnston D. Linking migration, mobility and HIV. Trop Med Int Health. 2010;15(12):1458-63.

18. Giorgio M, Townsend L, Zembe Y, Cheyip M, Guttmacher S, Carter R, et al. HIV prevalence and risk factors among male foreign migrants in Cape Town, South Africa. Aids Behav. 2017;21.7) -9ะ9:( $($ )

19.Foroughi M, Moayedi-Nia S, Shoghli A, Bayanolhagh S, Sedaghat A, Mohajeri M, et al. Prevalence of HIV, HBV and HCV among street and labour children in Tehran, Iran. Sex Transm Infect. 2017;93(6):421-3.

20.Kissinger P, Liddon N, Schmidt N, Curtin E, Salinas O, Narvaez A. HIV/STI risk behaviors among Latino migrant workers in New Orleans post-Hurricane Katrina disaster. Sex Transm Dis. 2008;35(11):924-9.

21.Saggurti N, Verma RK, Jain A, RamaRao S, Kumar KA, Subbiah A, et al. HIV risk behaviours among contracted and non-contracted male migrant workers in India: potential role of labour contractors and contractual systems in HIV prevention. AIDS. 2008;22:S127-S36.

22. Tiruneh K, Wasie B, Gonzalez H. Sexual behavior and vulnerability to HIV infection among seasonal migrant laborers in Metema district, northwest Ethiopia: a cross-sectional study. BMC Publ Health. 2015;15(1):122.

23.Yang B, Wu Z, Schimmele CM, Li S. HIV knowledge among male labor migrants in China. BMC Publ Health. 2015;15(1):323.

24.Mirzazadeh A, Nedjat S, Navadeh S, Haghdoost A, Mansournia M-A, McFarland W, et al. HIV and related risk behaviors among female sex workers in Iran: bias-adjusted estimates from the 2010 National Bio-Behavoral Survey. Aids Behav. 2014;18(1):19-24.

25.Mumtaz GR, Riedner G, Abu-Raddad LJ. The emerging face of the HIV epidemic in the Middle East and North Africa. Curr Opin HIV AIDS. 2014;9(2):183.

26.Brockerhoff M, Biddlecom AE. Migration, sexual behavior and the risk of HIV in Kenya. Int

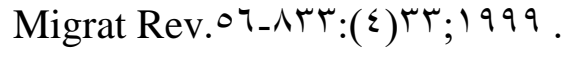

